\title{
Milk Replacer Acidification for Free-Access Feeding: Effects on the Performance and Health of Veal Calves
}

\author{
Cynthia G. Todd1, Ken E. Leslie', Suzanne T. Millman ${ }^{2 *}$, Jan M. Sargeant ${ }^{1,3}$, Heather Migdal4, \\ Kathleen Shore5, Neil G. Anderson', Trevor J. DeVries ${ }^{4}$ \\ ${ }^{1}$ Department of Population Medicine, Ontario Veterinary College, University of Guelph, Guelph, ON, Canada \\ ${ }^{2}$ Department of Veterinary Diagnostic \& Production Animal Medicine, lowa State University, Ames, IA, USA \\ ${ }^{3}$ Centre for Public Health and Zoonoses, University of Guelph, Guelph, ON, Canada \\ ${ }^{4}$ Department of Animal Biosciences, University of Guelph, Guelph, ON, Canada \\ ${ }^{5}$ Grober Nutrition, Cambridge, ON, Canada \\ ${ }^{6}$ Ontario Ministry of Agriculture, Food and Rural Affairs, Veterinary Science and Policy Unit, Elora, ON, Canada \\ Email: "smillman@iastate.edu
}

Received 1 July 2016; accepted 26 July 2016; published 29 July 2016

Copyright (C) 2016 by authors and Scientific Research Publishing Inc.

This work is licensed under the Creative Commons Attribution International License (CC BY).

http://creativecommons.org/licenses/by/4.0/

c) (i) Open Access

\section{Abstract}

Objectives of this study were to investigate the effects of milk replacer (MR) acidification for freeaccess feeding on pre- and post-weaning performance, morbidity and mortality of calves. Calves were randomly assigned to free-access feeding of acidified (ACID, $n=31$ ) or non-acidified (NON, $n$ = 31) MR, and weaned at 42 days. ACIDMR was prepared to $\mathrm{pH} 4.0$ - 4.5 using formic acid. Intakes were measured daily and weights weekly. Samples of ACID and NON MR were analyzed for coliform and aerobic bacterial growth. After weaning, calves transitioned to a grain-fed veal diet, weighed every 2 weeks. At slaughter (approximately 6 months of age), lungs were evaluated for gross pathological changes and dressed carcass weights were obtained. Generalized linear mixed models were constructed to examine the effects of MR acidification. Differences by treatment group for pre- and post-weaning morbidity and mortality were tested using Pearson's $\chi^{2}$ and Fisher's exact tests. ACID calves consumed less MR than NON $(10.6$ vs. $11.7 \mathrm{~L} / \mathrm{d}, P=0.02)$. Acidification tended to promote earlier onset of starter ration consumption $(32.0 \mathrm{vs}$. $39.5 \mathrm{~d}$, hazard ratio $=1.5, P=0.07$ ), but did not affect average daily starter ration or water intakes across the preweaning period. ACID and NON calves did not differ for BW at weaning, pre- or post-weaning ADG or dressed carcass weight. ACID MR had less coliform $(P<0.001)$ and aerobic bacterial growth $(P<$ 0.001) than NON MR, but odds of disease treatment and mortality did not differ. ACID calves tended to have lower odds of pulmonary lesions during post-mortem inspection than NON calves $(O R=0.3, P=0.07)$. These results indicate that under free-access feeding conditions, acidification

${ }^{*}$ Corresponding author.

How to cite this paper: Todd, C., Leslie, K.E., Millman, S.T., Sargeant, J.M., Migdal, H., Shore, K., Anderson, N.G. and DeVries, T.J. (2016) Milk Replacer Acidification for Free-Access Feeding: Effects on the Performance and Health of Veal Calves. Open Journal of Animal Sciences, 6, 234-246. http://dx.doi.org/10.4236/ojas.2016.63029 
limited bacterial growth and MR intake, but there were no long-term impacts of acidification on calf performance or health. In conclusion, acidification to $\mathrm{pH} 4.0-4.5$ will significantly reduce bacterial growth in milk fed to calves.

\section{Keywords}

\section{Acidified Milk Feeding, Free-Access Milk Feeding, Health, Growth, Veal Calves}

\section{Introduction}

Free-access milk feeding systems are increasingly adopted on dairy and veal farms [1] [2]. With these feeding systems, milk is available continuously allowing calves to feed ad libitum and to have greater control over their feeding behavior [3] [4]. In contrast, traditional feeding methods restrict milk intake, resulting in lower feed efficiency, reduced growth, hunger and reduced calf welfare [5]-[7].

Free-access milk is typically provided through use of automated milk feeders or by use of other teat-based systems where milk is typically stored in large batches. A practical challenge with free-access feeding is microbial growth when milk is kept at ambient temperatures [8]. Bacterial contamination of milk can increase the risk of pre-weaning morbidity and mortality, and negatively affect calf growth [9] [10]. Acidification is a preservation method used to control microbial growth in milk. Similarly, organic acids are added to feedstuffs, such as high moisture corn and silage, to prevent spoilage and preserve nutritional value [11] [12]. Some dairy and veal producers add acid to milk to inhibit microbial growth under free-access feeding conditions [13] [14]. The currently recommended that target $\mathrm{pH}$ for acidified milk is between 4.0 and 4.5. However, there is a need for research to validate whether this $\mathrm{pH}$ range is effective at limiting microbial growth under free-access feeding conditions in a commercial environment, and if this practice is associated with performance and health.

The objective of this study was to investigate effects of milk replacer (MR) acidification for free-access feeding on pre- and post-weaning performance, morbidity and mortality of veal calves. The hypothesis was that MR acidification would inhibit bacterial growth and support improved pre- and post-weaning calf health and performance.

\section{Materials and Methods}

Management conditions and experimental procedures described were in accordance with the guidelines of the Canadian Council on Animal Care (CCAC) [15]. All study procedures were approved by the University of Guelph Animal Care Committee.

\subsection{Animals, Housing and Management}

Sixty-two Holstein male calves were purchased from 4 commercial dairy farms in eastern Ontario, Canada. All calves received colostrum and were uniquely identified with Canadian Cattle Identification Agency tags at the source farm. Each calf was examined at the time of purchase by a research technician; only calves that were free from overt clinical signs of illness and did not receive any medication during the early postnatal period were enrolled in the study.

Calves were transported within $48 \mathrm{~h}$ of birth from the source farms to the University of Guelph, Kemptville Campus Dairy Education and Innovation Center (Kemptville, Ontario, Canada). On the morning of arrival, each calf was weighed using a calibrated livestock scale, its umbilicus was disinfected with $7 \%$ tincture of iodine and a blood sample was collected by jugular venipuncture (BD Vacutainer Blood Collection Tube, $10 \mathrm{~mL}$, without anticoagulant, Becton, Dickinson and Company, Franklin Lakes, New Jersey, USA). Blood samples were centrifuged (1500 $\times \mathrm{g}$ for 5 minutes at room temperature); serum was harvested and analyzed for serum total protein (TP) concentration by refractometry (Digital Refractometer \#300027, Sper Scientific, Scottsdale, Arizona, USA). Calves also received $2 \mathrm{~mL}$ of a vitamin A, D and E supplement (E-Master Sterile Injectable Solution, Vétoquinol Canada Inc., Lavaltrie, Quebec, Canada) and $1 \mathrm{~mL}$ of vitamin E/selenium (Dystosel Vitamin E-Selenium Injection, Pfizer Animal Health, Kirkland, Quebec, Canada). These injections were administered IM in the neck 
region.

Calves were tethered within individual polyethylene hutches (Poly Square Calf Nursery, Agri-Plastics, Grassie, Ontario, Canada) for the duration of the pre-weaning period. Hutches were located on a graded site with a gravel base. Hutch placement prevented physical contact between neighboring calves, but allowed animals to be within visual and auditory range of one another. The exterior of each hutch was painted white to provide solar protection for the calves. The interior of each hutch was bedded with wood shavings. Bedding material was replenished as needed, and fresh bedding was added at a minimum of once per week. All bedding material was removed from the site after each calf use; the hutch was cleaned and then repositioned on a new location. Calves remained in their hutches until 7 weeks of age, and then were moved to group housing in an open-faced barn for the post-weaning period (7 weeks of age to slaughter). In that facility, calves were comingled with 12 to 14 other individuals in pens $(10.8 \mathrm{~m} \times 6.9 \mathrm{~m})$ with bedding packs of wood shavings and straw.

Calves were neither castrated nor dehorned during this study. Ad libitum texturized starter feed (18\% Calf Starter with Monensin, Shur-Gain, St. Mary’s, Ontario, Canada) was available in an individual bucket to each calf from the day of arrival until movement to group housing. Calves were transitioned to a growing/finishing program for grain-fed veal upon entry to the post-weaning barn (Table 1). Water was available ad libitum throughout the pre-weaning period in an individual bucket in the hutch. Water was available ad libitum throughout the post-weaning period in a drinker. Forage was not offered to the calves.

\subsection{Experimental Design and Feeding Treatments}

Sample size calculations were completed (Intercooled Stata 9.1, College Station, Texas, USA) to estimate the number of calves required per treatment group to detect meaningful differences in pre-weaning calf growth and health outcomes. It was estimated that a total of 50 calves ( 25 calves/treatment group) would be needed to test the following a priori assumptions about pre-weaning calf growth performance: calves fed acidified MR vs. those fed non-acidified MR would have pre-weaning average daily gain (ADG, mean \pm SD) of $1.0 \pm 0.25 \mathrm{~kg} / \mathrm{day}$ and $0.8 \pm 0.25 \mathrm{~kg} /$ day, respectively, with a maximum type I error of $5 \%$ and type II error of $20 \%$. Alternatively, it was estimated that a total of 132 calves (66 calves/treatment group) would be needed to test the following $a$ priori assumptions about pre-weaning morbidity: 25\% of the calves fed acidified MR and 50\% of the calves fed non-acidified MR would be treated for at least one disease event during the pre-weaning period, with a maximum type I error of 5\% and type II error of $20 \%$. However, decisions about the sample size for this study were also dependent on the availability of newborn calves and housing facilities, as well as financial and labor resources. Thus, after taking into consideration all of these statistical and non-statistical factors, the research team determined that resource limitations would prevent the completion of a larger-scale study. A sample size of approximately 60 calves (30 calves/treatment group) was deemed feasible.

On the morning of arrival at the research facility, calves were randomly allocated to free-access feeding of: a) acidified (ACID) or b) non-acidified (NON) MR. The randomization sequence was generated by random draw in blocks of 4, prior to commencement of the study. Calves were fed their assigned MR feeding treatment for the duration of the pre-weaning period. Research technicians were responsible for the enrollment, management and feeding of the calves, detection of clinical disease and administration of health treatments, along with the collection of all health and performance data. Research technicians responsible for animal care were not blinded to treatment assignment.

Table 1. Summary of the growing/finishing feeding program for grain-fed veal production ${ }^{1}$.

\begin{tabular}{cccccc}
\hline \multirow{2}{*}{ Calf Weight } & Phase & \multicolumn{3}{c}{ Protein Supplement $^{2}$} \\
\cline { 3 - 5 } & Growing I & 36.0 & 0 & Fat, \% & Monensin sodium, mg $/ \mathrm{kg}$ \\
\hline$<135 \mathrm{~kg}$ & Growing II & 36.0 & 12.0 & 5.5 & 92 \\
135 to $180 \mathrm{~kg}$ & Finishing I & 36.0 & 12.0 & 5.5 & 106 \\
180 to $225 \mathrm{~kg}$ & Finishing II & 36.0 & 12.0 & 5.5 & 106 \\
$>225 \mathrm{~kg}$ & & &
\end{tabular}

${ }^{1}$ Calves had free-access to feed throughout all phases of feeding program. ${ }^{2}$ Protein supplement (36\% Red Veal Steakmaker and 36\% Opti-Glo Steakmaker, Shur-Gain, St. Marys, Ontario, Canada) was mixed with high-moisture corn: Growing I phase = 1 part protein supplement to 3 parts corn; Growing II phase $=1$ part protein supplement to 4 parts corn; Finishing I phase $=1$ part protein supplement to 5 parts corn; Finishing II phase $=1$ part protein supplement to 6 parts corn. ${ }^{3} \mathrm{CP}=$ crude protein. ${ }^{4} \mathrm{ECP}=$ equivalent crude protein from non-protein sources (i.e. urea). 
Calves were fed a non-medicated commercial MR (22\% CP and 17\% fat, Grober High Performance Calf Milk Replacer, Cambridge, Ontario, Canada). Milk replacer was prepared using a mixing rate of 150 g/L. Mixing directions were as follows: $150 \mathrm{~g}$ of powder was reconstituted in $0.25 \mathrm{~L}$ of hot water, $0.75 \mathrm{~L}$ of cold water was added and then the mixture was stirred vigorously. After preparation, MR was either fed immediately to the calves assigned to the NON treatment, or acidified and fed to the calves assigned to the ACID treatment. Acidified MR was prepared by cooling the MR to a temperature of less than $20^{\circ} \mathrm{C}$ and then stirring in pre-diluted formic acid (The Acidified Milk Solution, 9.8\% formic acid, NOD Apiary Products Ltd., Frankford, Ontario, Canada) until a pH between 4.0 and 4.5 was achieved. The temperature and $\mathrm{pH}$ of MR was measured using a waterproof combination tester (HI 98129 Combo pH, EC/TDS and Temperature Tester, Hanna Instruments, Laval, Quebec, Canada). The tester was rinsed with water after each use and cleaned each week with a cleaning solution (Hanna HI 7061 Electrode Cleaning Solution, Hanna Instruments, Laval, Quebec, Canada). The electrode of the tester was calibrated 3 times per week using standard buffer solutions of pH 4.01 and 7.01. Acidified MR was prepared in large batches and stored in enclosed plastic bins. After acidification, milk replacer was allowed to sit for a period of at least $5 \mathrm{~h}$ before being fed to the ACID calves. An automated stirring system, assembled from a paint mixer and electric drill connected to a timer, was programmed to slowly agitate the stored ACID MR for 15 min at 1200, 1800 and 2400 h each day. New batches of acidified MR were mixed at least every 48 h.

All calves were fed their assigned MR diet using a teat and bucket feeding system. Briefly, an artificial teat (Peach Teat, Skellerup Industries, Christchurch, New Zealand) was fastened to the interior of the hutch and attached to a plastic tube fitted with a weighted one-way valve. The plastic tube connected the teat to a $20 \mathrm{~L}$ polyethylene bucket with a sealable lid. The feeding bucket was positioned beside the hutch, enclosed within a wood box to protect the MR from direct exposure to sunlight. Milk replacer was added to the buckets at the morning and afternoon feedings (0700 and $1600 \mathrm{~h}$, respectively), and then replenished throughout the day as necessary. MR orts were weighed and then discarded at every feeding. To prevent MR separation, buckets were agitated by hand for approximately $10 \mathrm{~s}$ at 1000 and $1300 \mathrm{~h}$ daily. All feeding equipment, including teats, plastic tubes, buckets and lids were washed with detergent twice daily at morning and afternoon feedings, and allowed to air-dry. There were two sets of feeding equipment used to prevent delays in the delivery of MR to the calves. Calves were weaned by dilution of MR over a 5-day period. Specifically, beginning at the morning feeding at 38 days of age, the amount of water used for MR preparation was increased by $20 \%$ per day, which facilitated weaning at 6 weeks of age. Weaning decisions did not take into consideration the amount of starter ration consumed by the calf.

Samples of MR were collected from a subset of individual calf feeding buckets for bacterial testing weekly. Random number draw, blocked within treatment group, was used to determine buckets to be sampled each week. Separate random samples were drawn at morning and afternoon feedings to generate the list of feeding buckets to be sampled. Milk replacer samples were collected from $25 \%$ of buckets each week. Sampling was balanced for treatment group. At each feeding, immediately prior to orts being weighed and discarded, a sample of MR was collected directly from the bucket using standard flip-top vials (45 mL Lock Seal Vial, Capitol Vial Inc., Auburn, Alabama, USA). Each bucket was agitated for approximately $10 \mathrm{~s}$ before sample collection. Milk replacer that was sampled at the morning feeding had been offered to the calf at $1600 \mathrm{~h}$ on the previous day, and hence, had been exposed to ambient temperature conditions for approximately $15 \mathrm{~h}$. Milk replacer that was sampled at the afternoon feeding had been offered to the calf at $0700 \mathrm{~h}$ that same day, and hence, had been exposed to ambient temperature conditions for approximately $9 \mathrm{~h}$.

Milk replacer samples that were collected at morning feedings were submitted for bacteriological analysis on the morning of the same day, whereas samples collected at afternoon feedings were refrigerated at $4^{\circ} \mathrm{C}$ overnight and submitted on the following morning. For bacteriological analysis, serial dilutions (10 fold increments up to $\times 10^{8}$ ) of MR were prepared. Sterile water was used as the diluent. Diluted samples of MR were plated using 3 M Petrifilm Coliform Count Plates (CCP; 3 M Canada, London, Ontario, Canada) and 3 M Petrifilm Aerobic Count Plates (ACP; 3 M Canada, London, Ontario, Canada). Petrifilm CCP and ACP are ready-to-use culture medium systems for the enumeration of coliform and aerobic bacteria, respectively. The plates were inoculated with $1 \mathrm{~mL}$ of sample suspension from each serial dilution, as per manufacturer instructions, and then incubated (Hova-bator Turbofan Incubator, GQF Manufacturing Company Inc., Savannah, Georgia, USA) at $32^{\circ} \mathrm{C}$. The CCP and ACP were enumerated by a single technician after $24 \pm 1 \mathrm{~h}$ and $48 \pm 1 \mathrm{~h}$ of incubation, respectively. Any plate that had more than 250 colonies was recorded as too numerous to count (TNTC). The technician responsible for preparing and enumerating the plates was blind to treatment assignment. 


\subsection{Collection of Calf Performance and Health Data}

Milk replacer, starter ration and water intakes were determined daily for each calf from arrival until weaning. Calves were weighed weekly throughout the pre-weaning period, on the day of movement to post-weaning group housing, and every 2 weeks thereafter.

Fecal consistency and health were evaluated by 1 of 3 trained research technicians. Each calf was assigned a daily fecal consistency score from arrival until weaning. Fecal consistency was assessed using a 4-point scale (1 = normal, firm but not hard; 2 = soft, does not hold form; 3 = runny, spreads easily; 4 = watery, liquid consistency) [16]. To standardize fecal consistency scoring, descriptions and photographs for each point on the scale were provided to research technicians. In addition, calves were monitored daily for changes in appetite, attitude (general behavior and responsiveness), appearance, respiration and hydration. Rectal temperature was measured and a health assessment was completed using a standardized clinical scoring index [17] for any calf that was suspected of being clinically ill, based on a change in fecal consistency, appetite, attitude, appearance, respiration or hydration. The index evaluated the following clinical parameters: fever, fecal consistency, attitude, ear position, nasal and ocular discharge, cough and hydration status. Calves were assessed daily using the clinical scoring index until disease symptoms were no longer observed.

Disease detection and health treatment decisions were guided by information collected with the clinical scoring index. Fever was defined as a rectal temperature greater than $39.5^{\circ} \mathrm{C}$. Calves with a fever were treated with an injectable short-acting antibiotic (Excenel, ceftiofur sodium sterile powder for injection, Pfizer Animal Health, Kirkland, Quebec, Canada) for 3 to $5 \mathrm{~d}$. Calf diarrhea complex was defined as fecal consistency score of 4. Calves with calf diarrhea complex were treated with a combination of oral electrolyte solution (Calf-Lyte II, Vétoquinol, Lavaltrie, Quebec, Canada), injectable short-acting antibiotic (Excenel, ceftiofur sodium sterile powder for injection, Pfizer Animal Health, Kirkland, Quebec, Canada), neomycin sulfate boluses (Scour-plug, boluses for calf scours-pneumonia, Can-Vet Animal Health Supplies Ltd., Guelph, Ontario, Canada) and an absorbent anti-diarrheal demulcent (Endosorb Suspension, PRN Pharmacal, Pensacola, Florida, Canada) until clinical improvement was observed. Respiratory disease was defined as fever and at least one of the following clinical signs: nasal or ocular discharge, spontaneous or induced cough, ear droop, rough hair coat, lack of appetite, depression or lethargy. Calves with respiratory disease were treated with an injectable short-acting antibiotic for 3 to 5 days (Excenel, ceftiofur sodium sterile powder for injection, Pfizer Animal Health, Kirkland, Quebec, Canada). If clinical signs persisted, an injectable long-acting antibiotic (Bio-Mycin 200, oxytetracycline injection, Boehringer Ingelheim Vetmedica, Burlington, Ontario, Canada or Micotil, tilmicosin injection, Elanco Animal Health, Division Eli Lilly Canada Inc., Guelph, Ontario, Canada) was administered. Omphalophlebitis was defined as an enlarged umbilicus or purulent discharge from the umbilical structures. Calves with omphalophlebitis were treated with an injectable short-acting antibiotic (Procaine Penicillin G, Dominion Veterinary Laboratories Ltd., Winnipeg, Manitoba, Canada) until clinical improvement was observed. Any calf that died during the study was submitted to the University of Guelph Animal Health Laboratory (Kemptville, Ontario, Canada) for necropsy.

\subsection{Collection of Slaughter and Post-Mortem Pathology Data}

Calves were slaughtered at $186 \pm 9$ days of age at a provincially-licensed abattoir in eastern Ontario, Canada. On the afternoon prior to slaughter, calves were transported by livestock trailer approximately $130 \mathrm{~km}$ to the abattoir, and then housed in a group holding pen overnight. The following morning, beginning at $0800 \mathrm{~h}$, each calf entered the abattoir, was rendered insensible using a penetrating captive bolt pistol and exsanguinated by severing the jugular vein and carotid artery. After removal of hide and visceral organs, the carcass was trimmed, washed and the dressed weight was measured. Carcasses were subsequently marketed as grain-fed veal.

The pluck (lungs, heart, trachea and larynx) from each calf was harvested at slaughter and submitted for routine post-mortem inspection by the Canadian Food Inspection Agency meat inspector. The regional veterinarian approved release and transport of plucks from the abattoir to the University of Guelph Animal Health Laboratory (Kemptville, Ontario, Canada). Each pluck was evaluated for gross pathological changes by a board-certified veterinary pathologist. The cranial, middle and caudal lobes of the right and left lungs, and the accessory lobe were examined for lesions of pneumonia. All lesions were described for color and appearance, chronicity, size and location, as well as scored ( 1 = mild; 2 = moderate; 3 = marked; 4 = severe; no = not observed $)$ for consolidation, abscessation, bronchiectasis, sequestration and atelectasis. The bronchial lymph nodes were also ex- 
amined and any gross pathological findings were reported. The pathologist and all other staff at the laboratory and abattoir were blind to treatment assignment.

\subsection{Statistical Analysis}

All statistical analyses were performed using SAS 9.1 (SAS Institute Inc., Cary, North Carolina, USA). The main effect of interest for all analyses was MR acidification. Summary statistics and frequency tables were generated to compare the treatment groups for source farm, birth body weight (BW) and serum TP concentration; Student's $t$ test, Pearson's $\chi^{2}$ test and Fisher's exact test (expected count of less than 5 in any category) were used to assess for statistically significant differences at baseline.

Generalized linear mixed models were constructed to examine effects of MR acidification on MR bacteriology (coliform and aerobic bacterial counts) [18]. Coliform and aerobic bacterial counts were expressed on $\log _{10}$ scale and treated as continuous data. Any CCP or ACP that was recorded as TNTC was assigned a value that was 1.25 times greater than the highest count within the respective category. Milk bacteriology outcome variables were modeled with a normal distribution and an identity link, and included a random statement to account for correlation by sampling day.

Generalized linear mixed models were constructed to examine effects of MR acidification on calf performance outcome variables [18]. The primary outcome of interest was pre-weaning ADG, which was calculated using weekly BW measurements. The following additional calf performance outcome variables were evaluated: pre-weaning daily MR intake, pre-weaning daily starter ration intake, pre-weaning daily water intake, BW at weaning, post-weaning ADG (calculated from the bi-weekly BW measurements) and dressed carcass weight. All performance outcome variables were treated as continuous data. Each performance outcome variable, with the exception of BW at weaning and dressed carcass weight, was modeled with a normal distribution and an identity link, and included a repeated measures effect to account for within-calf correlation across measurements. Body weight at weaning and dressed carcass weight were measured at a single point in time, and modeled with a normal distribution and an identity link.

Time to onset of starter ration consumption was modeled using survival analysis [18]. Time to onset of starter ration consumption was defined as number of days until the calf consumed a minimum of $100 \mathrm{~g}$ of starter ration for 2 days consecutively. Kaplan-Meier survival estimates were generated for each treatment group, log-rank $\chi^{2}$ was used to test for differences by treatment group, and a Cox proportional hazards regression model was constructed. Any calf that died prior to satisfying the time to onset of starter ration consumption criteria was treated as a censored observation.

Milk replacer acidification was included, regardless of significance, in all models. Significance was declared at $\mathrm{P}<0.05$. All final models were evaluated for assumptions of homoscedasticity and normality of residuals. Homoscedasticity was assessed by visually examining a scatter-plot of the residuals against predicted values. Normality was assessed using histogram and normal probability plots, as well as checking residuals for skewness and kurtosis. A square-root transformation was applied to improve homoscedasticity and to help normalize distribution of residuals for the daily water intake model. Back-transformed means and $95 \%$ confidence intervals are presented. A natural log transformation was applied to improve homoscedasticity and to help normalize distribution of residuals for the daily starter ration intake model. Back-transformed means and $95 \%$ confidence intervals are presented. The fit of each generalized linear mixed model was examined by identifying the correlation structure that resulted in the smallest value of Akaike information criterion. A first-order autoregressive correlation structure was specified for the pre-weaning ADG model. A first-order heterogenous autoregressive correlation structure was specified for the daily MR intake, daily starter ration intake and daily water intake models. A Toeplitz heterogenous correlation structure was specified for the post-weaning ADG model.

Frequency tables were generated to examine effects of MR acidification on calf health. The following health outcome variables were evaluated: pre-and post-weaning cause-specific morbidity, mortality, pulmonary lesions at slaughter and enlarged bronchial lymph nodes. All health outcome variables were treated as categorical data. Pearson's $\chi^{2}$ test and Fisher's exact test (expected count of less than 5 in any category) were used to test for statistically significant differences between treatment groups.

\section{Results}

A total of 62 Holstein calves were enrolled on this study. Random allocation resulted in 31 calves per treatment 
group. One calf from each feeding treatment died during the pre-weaning period; both deaths were associated with cryptosporidiosis, enteritis, and dehydration. One ACID calf was euthanized in the post-weaning period because of an injury sustained during that time period. One NON calf died in the post-weaning period from effects of severe, chronic bronchopneumonia.

Source farm was not associated with treatment assignment $(P=0.54)$. Moreover, calves reared on the ACID and NON feeding treatments did not differ for birth BW (mean \pm SD: ACID $=47.0 \pm 5.1 \mathrm{~kg}$ and NON $=46.8 \pm$ $5.8 \mathrm{~kg}, P=0.89$ ) or serum TP concentration (mean $\pm \mathrm{SD}$ : ACID $=5.5 \pm 0.6 \mathrm{~g} / \mathrm{dL}$ and NON $=5.3 \pm 0.6 \mathrm{~g} / \mathrm{dL}, P$ $=0.25$ ). These summary data confirm that randomization to treatment groups resulted in similar calves at baseline for important growth and health characteristics.

Bacteriology was completed on 50 ACID and 50 NON MR samples. The ACID samples, had less coliform (LSM $\log _{10} \mathrm{cfu} / \mathrm{mL}, 95 \%$ confidence interval: $0.9,0.2$ to 1.6 vs. $4.8,4.1$ to $5.5, P<0.001$ ) and aerobic bacterial growth (LSM $\log _{10} \mathrm{cfu} / \mathrm{mL}, 95 \%$ confidence interval: $4.8,4.3$ to 5.2 vs. $7.7,7.2$ to $8.2, P<0.001$ ) than NON samples.

Pre-weaning daily MR intakes for calves assigned to the ACID and NON feeding treatments are presented in Figure 1. Acidification negatively affected daily MR intake (mean, 95\% confidence interval: ACID = 10.6, 9.9 to $11.2 \mathrm{~L} /$ day and NON $=11.7,11.0$ to $12.3 \mathrm{~L} /$ day, $P=0.02$ ). Median time to onset of starter ration consumption tended to be earlier for the ACID-treated vs. NON-treated calves ( 32.0 vs. 39.5 days, respectively; $P=0.07$; Figure 2). Daily probability of ACID-treated calves satisfying the criteria for onset of starter ration consumption tended to be 1.5 times greater than that of the NON-treated calves (hazard ratio, 95\% confidence interval: 1.5, 0.9 to $2.5, P=0.10$ ). However, once calves began actively consuming starter ration, daily starter ration intake did not differ by feeding treatment (Table 2). Calves reared on ACID and NON feeding treatments did not differ for pre-weaning water consumption, pre-or post-weaning ADG, BW at weaning or dressed carcass weight (Table 2).

Pre-weaning morbidity and mortality are summarized by feeding treatment in Table 3. Acidification did not affect odds of being treated for neonatal calf diarrhea complex between birth and weaning (OR, 95\% confidence interval: 1.8, 0.5 to 6.5). Mean age at onset of diarrhea for the ACID and NON-treated calves was 9.8 and 5.5 days, respectively $(P=0.06)$. The average number of days that the ACID and NON-treated calves required treatment for diarrhea was 6.4 and 7.2 days, respectively. The ACID and NON calves did not differ for the odds of being treated for pre-weaning respiratory disease (OR, 95\% confidence interval: $0.2,0.1$ to 1.7). Mean age at

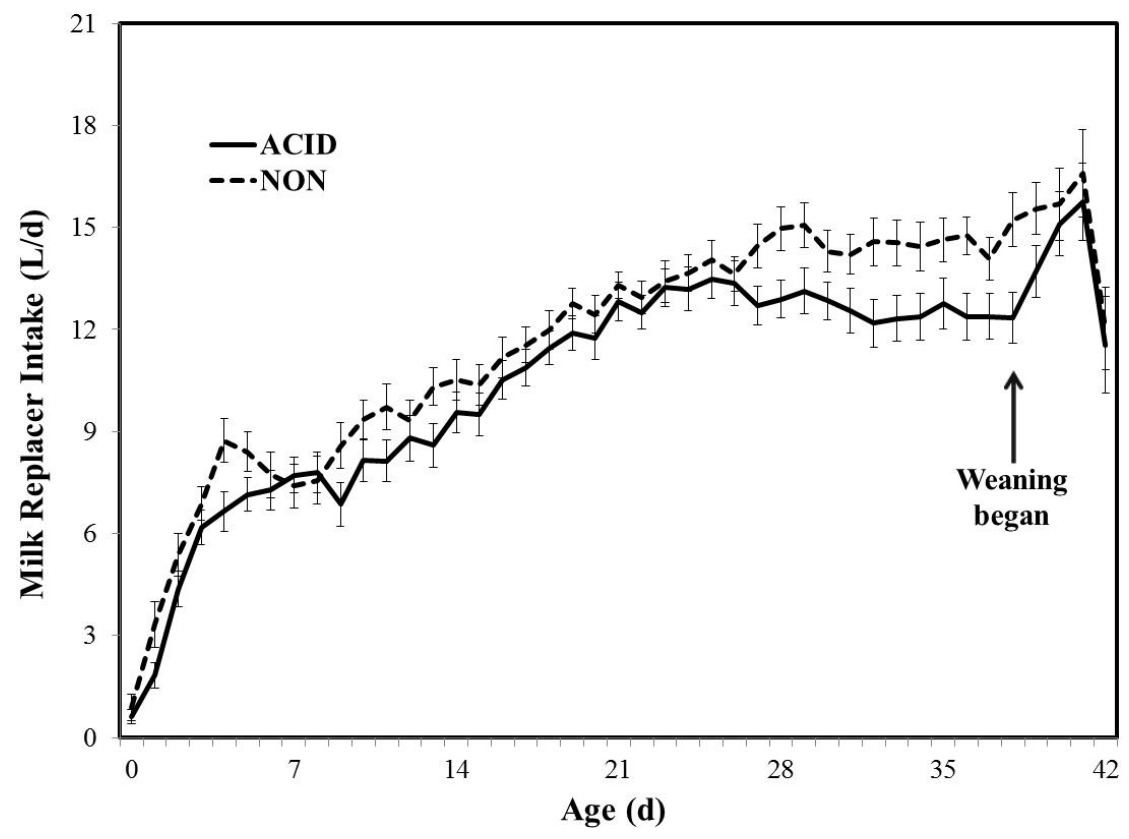

Figure 1. Daily milk replacer intakes (L/d; mean, SE) for calves assigned to freeaccess feeding of acidified (ACID) or non-acidified (NON) milk replacer. Calves were weaned over a 5-day interval by diluting the milk replacer $(20 \% / d)$ beginning at 38 days of age. 


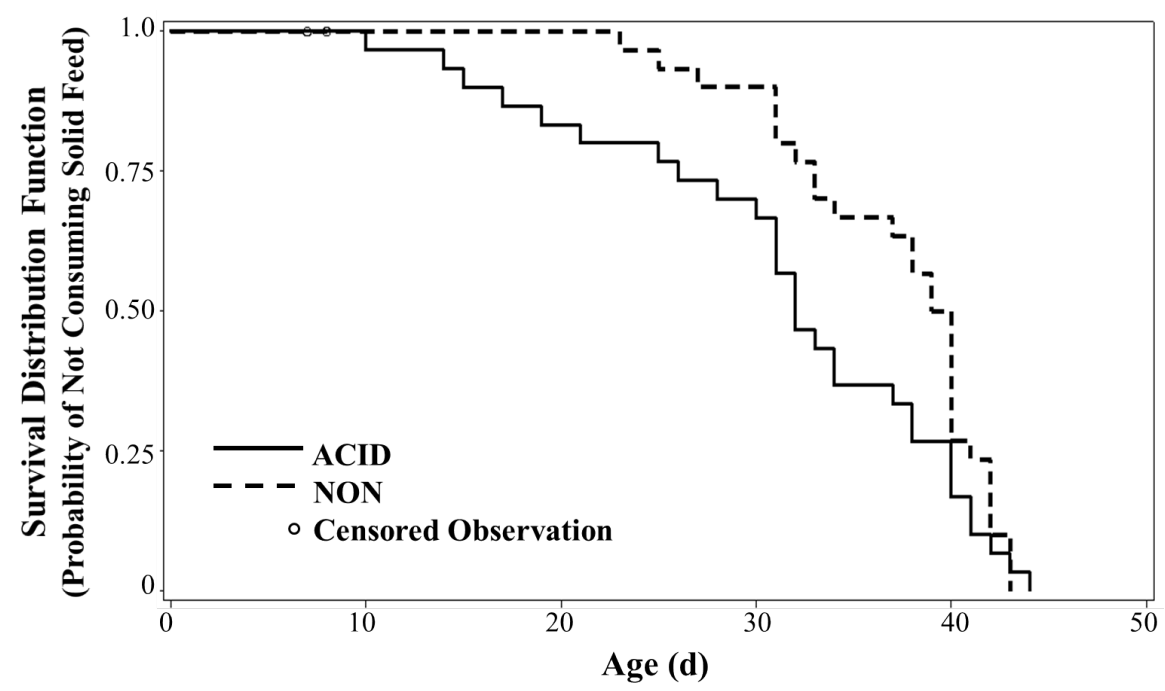

Figure 2. Kaplan-Meier survival curves for time to starter ration consumption for the calves assigned to free-access feeding of acidified (ACID) or non-acidified (NON) milk replacer. Calves satisfied the criteria for onset of starter ration consumption once they had consumed a minimum of $100 \mathrm{~g}$ of starter ration for 2 consecutive days. Two calves were treated as censored observations in this analysis; 1 ACID calf and 1 NON calf died at 8 and 7 days of age, respectively.

Table 2. Pre- and post-weaning intakes and growth for calves assigned to free-access feeding of acidified (ACID) or nonacidified (NON) milk replacer ${ }^{1}$.

\begin{tabular}{|c|c|c|c|}
\hline \multirow{2}{*}{ Outcome } & \multicolumn{2}{|c|}{ Treatment } & \multirow[t]{2}{*}{$P$-value } \\
\hline & ACID & NON & \\
\hline \multicolumn{4}{|l|}{ Preweaning ${ }^{2}$} \\
\hline Number of calves, $n$ & 31 & 31 & \\
\hline Daily starter ration intake ${ }^{3}, \mathrm{~kg} / \mathrm{d}$ & $0.15(0.13,0.19)$ & $0.18(0.14,0.24)$ & 0.32 \\
\hline Daily water intake, $\mathrm{L} / \mathrm{d}$ & $1.6(1.4,1.7)$ & $1.4(1.3,1.6)$ & 0.15 \\
\hline $\mathrm{ADG}, \mathrm{kg} / \mathrm{d}$ & $0.9(0.8,1.0)$ & $1.0(0.9,1.1)$ & 0.18 \\
\hline BW at weaning, $\mathrm{kg}$ & $82.4(79.0,85.8)$ & $85.7(82.2,89.1)$ & 0.18 \\
\hline \multicolumn{4}{|l|}{ Postweaning $^{4}$} \\
\hline Number of calves, $\mathrm{n}$ & 30 & 30 & \\
\hline Postweaning ADG, kg/d & $1.4(1.3,1.5)$ & $1.4(1.3,1.5)$ & 0.83 \\
\hline Dressed carcass weight, $\mathrm{kg}$ & $146.7(140.5,152.9)$ & $145.4(139.2,151.6)$ & 0.76 \\
\hline
\end{tabular}

${ }^{1}$ Least square mean (95\% confidence interval) are presented. ${ }^{2}$ Preweaning data were collected from arrival until weaning at 42 days of age. ${ }^{3}$ Daily starter ration intake (as-fed) was adjusted for time until onset of starter ration consumption criteria was satisfied. ${ }^{4}$ Postweaning data were collected from 43 days of age until slaughter.

onset of respiratory disease for the ACID and NON-treated calves was 26.0 and 30.2 days, respectively. Two calves (1 ACID and $1 \mathrm{NON}$ ) presented with clinical signs consistent with severe, chronic respiratory disease that required extended treatment with a long-acting antibiotic; all other cases of respiratory disease were resolved by administering the standardized therapeutic protocol. Acidification did not influence the odds of omphalophlebitis (OR, 95\% confidence interval: 0.6, 0.1 to 4.3) or non-specific fever (OR, 95\% confidence interval: 1.6, 0.2 to 10.4), or overall pre-weaning mortality (OR, 95\% confidence interval: 1.0, 0.1 to 17.7).

Post-weaning morbidity and mortality by treatment group are reported in Table 3 . There was 1 ACID calf and 1 NON calf that required treatment for post-weaning respiratory disease. The ACID calf exhibited signs of respiratory disease and bloat, required surgery and then received a regimen of systemic antibiotics. The NON calf required extended treatment with short-acting and then long-acting antibiotics. This calf died and necropsy 
Table 3. Pre- and post-weaning morbidity and mortality for calves assigned to free-access feeding of acidified (ACID) or non-acidified (NON) milk replacer.

\begin{tabular}{|c|c|c|c|}
\hline \multirow{2}{*}{ Outcome } & \multicolumn{2}{|c|}{ Treatment } & \multirow[t]{2}{*}{$P$-value } \\
\hline & ACID & NON & \\
\hline \multicolumn{4}{|l|}{ Pre-weaning ${ }^{1}$} \\
\hline Number of calves, $n$ & 31 & 31 & \\
\hline Diarrhea incidence risk, \% (no. cases) & $83.9(26)$ & $74.2(23)$ & 0.54 \\
\hline Age at Onset of Diarrhea, days & $9.8(7.0)$ & $5.5(3.1)$ & 0.06 \\
\hline Respiratory disease incidence risk, \% (no. cases) & $3.2(1)$ & $16.1(5)$ & 0.20 \\
\hline Omphalophlebitis incidence risk, \% (no. cases) & $6.5(2)$ & $9.7(3)$ & 1.00 \\
\hline Fever incidence risk, \% (no. cases) & $9.7(3)$ & $6.5(2)$ & 1.00 \\
\hline Mortality incidence risk, \% (no. cases) & $3.2(1)$ & $3.2(1)$ & 1.00 \\
\hline \multicolumn{4}{|l|}{ Post-weaning $^{3}$} \\
\hline Number of calves, $\mathrm{n}$ & 30 & 30 & \\
\hline Respiratory disease incidence risk, \% (no. cases) & $3.3(1)$ & $3.3(1)^{\mathrm{A}}$ & 1.00 \\
\hline Vomiting incidence risk, \% (no. cases) & $3.3(1)$ & $3.3(1)$ & 1.00 \\
\hline Injury incidence risk, \% (no. cases) & $3.3(1)^{\mathrm{B}}$ & 0 & 0.98 \\
\hline
\end{tabular}

${ }^{1}$ Preweaning data were collected from arrival until weaning at 42 days of age. ${ }^{2}$ Mean (SD). ${ }^{3}$ Postweaning data were collected from 43 days of age until slaughter. ${ }^{\mathrm{A}}$ Died. ${ }^{\mathrm{B}}$ Euthanized under recommendation by the staff veterinarian.

established that death was associated with severe, chronic bronchopneumonia. There was 1 calf from each treatment group that developed projectile eructation and diarrhea following weaning, which persisted from 2 days to 2 weeks, but resolved with supportive therapy. One ACID calf was injured after milk weaning, unable to bear weight, and subsequently euthanized under recommendation by the staff veterinarian. Necropsy established that the calf suffered from thoracic muscle and vertebral abscessation and osteomyelitis, as well as spinal cord compression and myelomalacia.

Calves assigned to the ACID treatment tended to have lower odds of pulmonary lesions during post-mortem inspection, as compared with NON-treated calves (OR, 95\% confidence interval: $0.3,0.1$ to $1.0, P=0.07$ ). Overall, 4 of 29 (13.8\%) ACID-treated calves vs. 11 of 29 (37.9\%) NON-treated calves had lesions consistent with respiratory disease. Of these calves with lesions, the severity was generally mild (3 of 4 ACID calves and 9 of 11 NON calves). Lesions in the other 3 calves were characterized as moderate to markedly severe. For chronicity of the disease process, 3 of 4 ACID calves and 6 of 11 NON calves were described as having chronic lesions. Moreover, lesions involved multiple lobes of the lung for 1 ACID-treated calf and 8 NON-treated calves. Calves did not differ by treatment for the odds of having enlarged bronchial lymph nodes (ACID: 1 of 29 vs. NON: 3 of 29, OR, 95\% confidence interval: $0.9,0.1$ to $16.0, P=0.61$ ).

\section{Discussion}

The hypothesis underlying this study was that acidification would reduce $\mathrm{MR} \mathrm{pH}$ and create unfavorable conditions for bacterial growth, thereby allowing MR to be safely fed in a free-access manner to calves. The bacteriological goals for milk intended for calf consumption are as follows: no coliform growth and a total bacterial count of less than $10,000 \mathrm{cfu} / \mathrm{mL}$ [17]. Although ACID MR samples had several $\log _{10} \mathrm{cfu} / \mathrm{mL}$ fewer bacteria than the NON samples on average, some ACID samples did not meet these recommended bacteriological goals. None of NON MR samples reached these recommended goals. Furthermore, aerobic bacterial counts for the NON MR samples were as high as the reported number of viable bacteria found in waste milk [19]. Thus, calves assigned to the ACID feeding treatment were exposed to fewer coliform and aerobic bacteria in MR than NON calves, butacidification with formic acid to a target $\mathrm{pH}$ between 4.0 and 4.5 was not always effective at preserving MR. Environmental conditions were likely a major contributing factor to elevated bacterial counts. This study was conducted between May and February, with all calves completing the pre-weaning stage during the summer months. The daily minimum and maximum ambient temperatures during the pre-weaning stage ranged 
from $-1.0^{\circ} \mathrm{C}$ to $23.0^{\circ} \mathrm{C}$ (mean $\pm \mathrm{SD}: 12.3^{\circ} \mathrm{C} \pm 5.3$ ) and 17.0 to $41.0^{\circ} \mathrm{C}$ (mean \pm SD: $29.3^{\circ} \mathrm{C} \pm 5.4$ ), respectively. The authors conducted a similar study on free-access feeding of acidified MR earlier in the year, during cooler winter and spring months when daily minimum and maximum temperatures ranged from $-24.2^{\circ} \mathrm{C}$ to $13.9^{\circ} \mathrm{C}$ (mean \pm SD: $-1.2^{\circ} \mathrm{C} \pm 9.0$ ) and $-7.4^{\circ} \mathrm{C}$ to $23.1^{\circ} \mathrm{C}$ (mean $\pm \mathrm{SD}: 7.8^{\circ} \mathrm{C} \pm 8.8$ ), respectively [2]. Under those conditions, mean (95\% confidence interval) aerobic bacterial counts for samples of acidified and non-acidified MR were $2.1 \mathrm{cfu} / \mathrm{mL}$ (1.9 to $2.2 \mathrm{cfu} / \mathrm{mL}$ ) and $2.7 \mathrm{cfu} / \mathrm{mL}$ (2.6 to $2.8 \mathrm{cfu} / \mathrm{mL}$ ), respectively, and there was no coliform growth [2]. Acidification helps to maintain the bacteriological quality of milk when it is fed under free-access conditions, but additional preservative interventions may be needed during warmer weather.

Pre-weaning MR intakes reported here are similar to other reports where calves were offered unlimited quantities of [3] [4] [7] [20]. Daily MR intake by calves assigned to the ACID feeding treatment was approximately 1 L/day less than that of NON calves. However, calves in both treatments voluntarily consumed, beginning the first week of life, more MR than what is offered under traditional restricted (8 to $10 \%$ of birth BW) feeding conditions [4] [7] [21]. These findings are consistent with research in which calves were given free-access to colostrum acidified to $\mathrm{pH}$ between 4.3 and 4.4 [22], but differ from another study where DMI of MR under freeaccess feeding conditions was not affected by acidification to $\mathrm{pH} 5.8$ [23]. Hill et al. [24] reported that calves fed MR acidified to $\mathrm{pH} 4.2$ consumed less MR than calves fed MR with pH 5.2. Depression of MR consumption could beassociated with taste of the acidified MR, since calves are sensitive to changes in acidity. Goatcher and Church [25] documented that calves exhibit a moderate preference for acid solutions at $\mathrm{pH}$ 4.4, but this preference quickly disappeared with declining $\mathrm{pH}$ levels, and calves rejected solutions at $\mathrm{pH}$ 3.6. Moreover, calves consuming MR acidified to a target $\mathrm{pH}$ between 4.0 and 4.5 exhibited more frequent meals than calves fed non-acidified MR, suggesting acidification may reduce palatability [2]. Another consideration is that the MR used in the current study had a large proportion of skim milk, which would clot below $\mathrm{pH}$ 5.3. Hence, there may have been differences in the texture of the ACID vs. NON MR fed to the calves, which could have contributed to the depressed MR intakes. This area of research warrants further investigation. Furthermore, it is interesting to note that both the ACID and NON calves increased their daily MR intake over the 5-day weaning period. This suggests that calves may have been attempting to maintain similar intakes of dry matter from their liquid diet during the weaning phase.

Contrary to our hypothesis, milk replacer acidification did not impact growth performance. Calves enrolled on the current study had similar weight gains compared to that reported elsewhere [3] [4] [21] [26]. Calves assigned to the ACID MR feeding treatment tended to begin consuming starter ration earlier than the NON-fed calves, and this corresponded with the time period where calves showed the largest difference in MR intake (Figure 1). Although earlier onset of starter ration consumption could have implications for rumen development, calves did not differ by feeding treatment for pre-weaning weight gain. There were no differences in post-weaning weight gain or dressed carcass weight by feeding treatment. The lack of post-weaning growth performance differences can likely be attributed to the ACID and NON calves being managed the same after weaning and movement to post-weaning housing. Huuskonen et al. [27] reported carcass weights did not differ among calves fed acidified milk at daily allowances between 6.0 and $10.0 \mathrm{~L} / \mathrm{d}$; however, these calves had greater carcass weights than calves fed restricted non-acidified MR.

Despite ACID calves being exposed to fewer aerobic and coliform bacteria, health benefits were not observed during the pre-weaning period. Fallon and Harte [23] found that calves with free-access to acidified MR had lower pre-weaning morbidity and mortality than calves fed non-acidified MR. The lack of significant differences for the health outcome variables in the current study may be attributed to sample size and elevated risk of type II error. Hence, a larger-scale randomized controlled trial or field study is still needed to better determine calf health effects of MR acidification at the target $\mathrm{pH}$ range between 4.0 and 4.5.

Results of this study suggest that free-access feeding of acidified MR may be associated with improved respiratory health. Post-mortem inspection of the calves' lungs and bronchial lymph nodes showed a tendency for fewer pulmonary lesions consistent with respiratory disease in ACID calves. Leruste et al. [28] reported that clinical signs of respiratory disease, together with pulmonary lesions at slaughter, provide a better indication of the respiratory health of calves compared to clinical observation alone. Since the time sequence of these lesions is unknown, it cannot be established whether lesions were associated with management during the pre-or postweaning periods. Numerically, more calves in the NON feeding group required treatment for respiratory illness during the pre-weaning period, and additional diagnostic procedures, such as thoracic ultrasonography [29] [30], bronchoalveolar lavage or nasopharyngeal swabs [31] would be helpful in future research to evaluate the time 
sequence of respiratory disease, and to better assess health status.

One of the main limitations of this study was that research technicians responsible for animal care, collection of performance data, assessment of health status and administration of treatments were not blinded to treatment group. Bias may have increased the potential for differential misclassification or measurement error in outcome assessment. However, all abattoir and laboratory staff were blind to treatment assignment, reducing likelihood of information bias in slaughter and post-mortem results. The second limitation of this study is the relatively small sample size that increased the potential of Type II errors. Although this study did not have sufficient statistical power to evaluate differences in morbidity, observed differences and variability for health outcome variables are reported for utility in planning and design of future research projects on this topic.

\section{Conclusion}

In conclusion, results from this study established that acidifying MR with formic acid to the target $\mathrm{pH}$ ranging between 4.0 and 4.5 reduced growth of coliform and aerobic bacteria, but did not reliably preserve MR when it was fed free-access to calves during summer months. Under free-access feeding conditions, MR acidification was associated with reduced MR consumption, but did not affect the long-term growth performance or health of veal calves.

\section{Acknowledgements}

Financial support for this study was generously provided by Natural Sciences and Engineering Research Council of Canada (Ottawa, Ontario, Canada), Ontario Ministry of Agriculture, Food and Rural Affairs (Guelph, Ontario, Canada), Dairy Farmers of Ontario (Mississauga, Ontario, Canada) and Ontario Veal Association (Guelph, Ontario, Canada). In-kind support for this was study was generously provided by Grober Nutrition (Cambridge, Ontario, Canada) and 3M Canada (London, Ontario, Canada). The authors wish to thank Albert Koekkoek, Carolyn Innes, and the staff of the Kemptville Campus Dairy Education and Innovation Center for technical support, William Sears (Department of Population Medicine, Guelph, Ontario, Canada) for his advice on statistical analyses, and Andre Roy (Grober Nutrition, Cambridge, Ontario, Canada) for his input during the planning of this study.

\section{Conflict of Interest Statement}

The authors declare no conflict of interest for this study.

\section{References}

[1] Khan, M.A., Weary, D.M. and von Keyserlingk, M.A.G. (2011) Invited Review: Effects of Milk Ration on Solid Feed Intake, Weaning, and Performance in Dairy Heifers. Journal of Dairy Science, 94, 1071-1081. http://dx.doi.org/10.3168/jds.2010-3733

[2] Todd, C.G. (2013) An Investigation into the Effects of Free-Access Acidified Milk Replacer Feeding Programs on the Productivity and Welfare of the Calf. PhD Dissertation, University of Guelph, Guelph, Ontario, Canada.

[3] Appleby, M.C., Weary, D.M. and Chua, B. (2001) Performance and Feeding Behaviour of Calves on ad libitum Milk from Artificial Teats. Applied Animal Behaviour Science, 74, 191-201. http://dx.doi.org/10.1016/S0168-1591(01)00171-X

[4] Borderas, T.F., de Passillé, A.M.B. and Rushen, J. (2009) Feeding Behaviour of Calves Fed Small or Large Amounts of Milk. Journal of Dairy Science, 92, 2843-2852. http://dx.doi.org/10.3168/jds.2008-1886

[5] Diaz, M.C., Van Amburgh, M.E., Smith, J.M., Kelsey, J.M. and Hutten, E.L. (2001) Composition of Growth of Holstein Calves Fed Milk Replacer from Birth to 105-Kilogram Body Weight. Journal of Dairy Science, 84, 830-842. http://dx.doi.org/10.3168/jds.S0022-0302(01)74541-9

[6] Khan, M.A., Lee, H.J., Lee, W.S., Kim, H.S., Ki, K.S., Hur, T.Y., Suh, G.H., Kang, S.J. and Choi, Y.J. (2007) Structural Growth, Rumen Development, and Metabolic and Immune Responses of Holstein Male Calves Fed Milk through Step-Down and Conventional Methods. Journal of Dairy Science, 90, 3376-3387. http://dx.doi.org/10.3168/jds.2007-0104

[7] De Paula Vieira, A., Guesdon, V., de Passillé, A.M., von Keyserlingk, M.A.G. and Weary, D.M. (2008) Behavioural Indicators of Hunger in Dairy Calves. Applied Animal Behaviour Science, 109, 180-189. http://dx.doi.org/10.1016/j.applanim.2007.03.006 
[8] Stewart, S., Godden, S., Bey, R., Rapnicki, P., Fetrow, J., Farnsworth, R., Scanlon, M, Arnold, Y., Clow, L., Mueller, K. and Ferrouillet, C. (2005) Preventing Bacterial Contamination and Proliferation during the Harvest, Storage, and Feeding of Fresh Bovine Colostrum. Journal of Dairy Science, 88, 2571-2578. http://dx.doi.org/10.3168/jds.S0022-0302(05)72933-7

[9] Jamaluddin, A.A., Carpenter, T.E., Hird, D.W. and Thurmond, M.C. (1996) Economics of Feeding Pasteurized Colostrum and Pasteurized Waste Milk to Dairy Calves. Journal of the American Veterinary Medical Association, 209, 751756.

[10] Jamaluddin, A.A., Hird, D.W., Thurmond, M.C. and Carpenter, T.E. (1996) Effect of Preweaning Feeding of Pasteurized and Nonpasteurized Milk on Postweaning Weight Gain of Heifer Calves on a Californian Dairy. Preventive Veterinary Medicine, 28, 91-99. http://dx.doi.org/10.1016/0167-5877(96)01040-9

[11] Britt, D.G. and Huber, J.T. (1976) Preservation of and Animal Performance on High Moisture Corn Treated with Ammonia or Propionic Acid. Journal of Dairy Science, 59, 668-674. http://dx.doi.org/10.3168/jds.S0022-0302(76)84256-7

[12] Argagón, Y.A. (2007) The Use of Acids to Preserve Feedstuffs. In: Lückstädt, C., Ed., Acidifiers in Animal Nutrition: A Guide for Feed Preservation and Acidification to Promote Animal Performance, Nottingham University Press, Nottingham, United Kingdom, 79-86.

[13] Anderson, N. (2006) OMAFRA Infosheet: Mimicking Nature’s Way for Milk-Fed Dairy Calves-Free-Access Feeding with Acidified Milk.

[14] Anderson, N. (2008) OMAFRA Infosheet: Free-Access Feeding of Acidified Milk-Setting up the System Using Formic Acid.

[15] CCAC (2009) CCAC Guidelines on: The Care and Use of Farm Animals in Research, Teaching and Testing. http://www.ccac.ca/Documents/Standards/Guidelines/Farm_Animals.pdf

[16] Larson, L.L., Owen, F.G., Albright, J.L., Appleman, R.D., Lamb, R.C. and Miller, L.D. (1977) Guidelines toward More Uniformity in Measuring and Reporting Calf Experimental Data. Journal of Dairy Science, 60, 989-991. http://dx.doi.org/10.3168/jds.S0022-0302(77)83975-1

[17] McGuirk, S.M. (2008) Disease Management of Dairy Calves and Heifers. Veterinary Clinics of North America: Food Animal Practice, 24, 139-153. http://dx.doi.org/10.1016/j.cvfa.2007.10.003

[18] Dohoo, I., Martin, W. and Stryhn, H. (2010) Veterinary Epidemiologic Research. VER Inc., Charlottetown.

[19] Selim, S.A. and Cullor, J.S. (1997) Number of Viable Bacteria and Presumptive Antibiotic Residues in Milk Fed to Calves on Commercial Dairies. Journal of the American Veterinary Medical Association, 211, 1029-1035.

[20] Miller-Cushon, E.K., Bergeron, R., Leslie, K.E. and De Vries, T.J. (2013) Effect of Milk Feeding Level on Development of Feeding Behavior in Dairy Calves. Journal of Dairy Science, 96, 551-564. http://dx.doi.org/10.3168/jds.2012-5937

[21] Jasper, J. and Weary, D.M. (2002) Effects of ad Libitum Milk Intake on Dairy Calves. Journal of Dairy Science, 85, 3054-3058. http://dx.doi.org/10.3168/jds.S0022-0302(02)74391-9

[22] Collings, L.K.M., Proudfoot, K.L. and Veira, D.M. (2011) The Effects of Feeding Untreated and Formic Acid-Treated Colostrum ad Libitum on Intake and Immunoglobulin Levels in Dairy Calves. Canadian Journal of Animal Science, 91, 55-59. http://dx.doi.org/10.4141/CJAS10043

[23] Fallon, R.J. and Harte, F.J. (1988) Effect of Normal or Acidified Milk Replacer Offered ad Libitum on Calf Performance. Irish Journal of Agricultural Research, 27, 123-130.

[24] Hill, T.M., Bateman, H.G., Aldrich, J.M., Quigley, J.D. and Schlotterbeck, R.L. (2013) Evaluation of ad Libitum Acidified Milk Replacer Programs for Dairy Calves. Journal of Dairy Science, 96, 3153-3162. http://dx.doi.org/10.3168/jds.2012-6132

[25] Goatcher, W.D. and Church, D.C. (1970) Taste Responses in Ruminants. III. Reactions of Pygmy Goats, Normal Goats, Sheep and Cattle to Acetic Acid and Quinine Hydrochloride. Journal of Animal Science, 31, 373-382.

[26] Khan, M.A., Lee, H.J., Lee, W.S., Kim, H.S., Kim, S.B., Ki, K.S., Ha, J.K., Lee, H.G. and Choi. Y.J. (2007) Pre- and Postweaning Performance of Holstein Female Calves Fed Milk through Step-Down and Conventional Methods. Journal of Dairy Science, 90, 876-885. http://dx.doi.org/10.3168/jds.S0022-0302(07)71571-0

[27] Huuskonen, A., Huumonen, M., Joki-Tokola, E. and Tuomisto, L. (2011) Effects of Different Liquid Feeding Strategies during the Pre-Weaning Period on the Performance and Carcass of Dairy Bull Calves. Acta Agriculturae Scandinavica, Section A, 61, 187-195. http://dx.doi.org/10.1080/09064702.2011.645863

[28] Leruste, H., Brscic, M., Heutinck, L.F.M., Visser, E.K., Wolthuis-Fillerup, M., Bokkers, E.A.M., Stockhofe-Zurwieden, N., Cozzi, G., Gottardo, F., Lensink. B.J. and van Reenen, C.G. (2012) The Relationship between Clinical Signs of Respiratory System Disorders and Lung Lesions at Slaughter in Veal Calves. Preventive Veterinary Medicine, 105, 93100. http://dx.doi.org/10.1016/j.prevetmed.2012.01.015 
[29] Ollivett, T.L., Burton, A.J., Bicalho, R.C. and Nydam, D.V. (2011) Use of Rapid Thoracic Ultrasonography for Detection of Subclinical and Clinical Pneumonia in Dairy Calves. Proceedings of the Annual Meeting of the American Association of Bovine Practitioner, 44, 148.

[30] Buczinski, S., Forte, G. and Belanger, A.M. (2013) Ultrasonographic Assessment of the Thorax as a Fast Technique to Assess Pulmonary Lesions in Dairy Calves with Bovine Respiratory Disease. Journal of Dairy Science, 96, 4523-4528. tp://dx.doi.org/10.3168/jds.2013-6577

[31] Allen, J.W., Viel, L., Bateman, K.G., Rosendal, S., Shewen, P.E. and Physick-Sheard, P. (1991) The Microbial Flora of the Respiratory Tract in Feedlot Calves: Associations between Nasopharyngeal and Bronchoalveolar Lavage Cultures. Canadian Journal of Veterinary Research, 55, 341-346.

\section{Submit or recommend next manuscript to SCIRP and we will provide best service for you:}

Accepting pre-submission inquiries through Email, Facebook, LinkedIn, Twitter, etc.

A wide selection of journals (inclusive of 9 subjects, more than 200 journals)

Providing 24-hour high-quality service

User-friendly online submission system

Fair and swift peer-review system

Efficient typesetting and proofreading procedure

Display of the result of downloads and visits, as well as the number of cited articles

Maximum dissemination of your research work

Submit your manuscript at: http://papersubmission.scirp.org/ 